Sawala - Jurnal Administrasi Negara

ISSN: 2598-4039 (Online)

ISSN: 2302-2221 (Print)

Volume 9 Number 2 December 2021

Page $125-140$
Copyright $(\odot) 2021$, Verto Septiandika, Nur Halima. This is an open access article under the CC-BY

NC-SA license

http:// DOI 10.30656/sawala.v9i2.3420

\title{
INDEKS KEPUASAN MASYARAKAT TERHADAP KUALITAS PELAYANAN PROGRAM DEMANG DIMMAS (KADEMANGAN DIGITAL MELAYANI MASYARAKAT) DI KELURAHAN KETAPANG KECAMATAN KADEMANGAN KOTA PROBOLINGGO
}

Verto Septiandika, Nur Halima*

Fakultas Ilmu Sosial dan Ilmu Politik Universitas Panca Marga Probolinggo

\section{Abstract}

This study aims to determine the level of community satisfaction with the quality of service innovation of the Demang Dimmas Program (Kademangan Digital Melayani Masyarakat) in Ketapang Village, Kademangan District, Probolinggo City. In this study the method used is descriptive quantitative, in accordance with the formulation of the problem that is descriptive. Quantitative research is descriptive and tends to use an inductive approach to analysis. The sampling technique used in this study is a nonprobability sampling technique with the type of accidental sampling, namely the technique of determining the sample based on the spontaneity factor. The research sample is targeted at 100 respondents according to the minimum number of respondents in the preparation of the Community Satisfaction Index which was chosen accidentally. Based on the calculation of the Community Satisfaction Index, the service quality of the Demang Dimmas Program (Kademangan Digital Melayani Masyarakat) in Ketapang Village, Kademangan District, Probolinggo City obtained an IKM conversion result of 69.19. The performance of the service unit of the Demang Dimmas Program (Kademangan Digital Melayani Masyarakat) in Ketapang Village, Kademangan District, Probolinggo City is in the "C" service quality with the "Poor Good" category.

Keywords: community satisfaction index, public service innovation

Article History:

Submission June 222021

Revised October 072021

Accepted October 302021

Published December 012021

${ }^{*}$ Corresponding author

Email:

nurhalima2346@gmail.com
\end{abstract}

\begin{abstract}
Abstrak
Penelitian ini bertujuan untuk mengetahui tingkat kepuasan masyarakat terhadap kualitas inovasi pelayanan Program Demang Dimmas (Kademangan Digital Melayani Masyarakat) di Kelurahan Ketapang Kecamatan Kademangan Kota Probolinggo. Dalam penelitian ini metode yang digunakan adalah deskriptif kuantitatif, sesuai dengan rumusan masalah yang bersifat deskriptif. Penelitian kuantitatif bersifat deskriptif dan cenderung menggunakan analisis pendekatan induktif. Teknik sampling yang digunakan dalam penelitian ini adalah teknik non-probability sampling dengan jenis accidental sampling, yaitu teknik penentuan sampel berdasarkan faktor spontanitas, Sampel penelitian ditargetkan berjumlah 100 responden sesuai dengan jumlah minimal responden dalam penyusunan Indeks Kepuasan Masyarakat yang dipilih secara tidak sengaja. Berdasarkan perhitungan Indeks Kepuasan Masyarakat, maka kualitas layanan Program Demang Dimmas (Kademangan Digital Melayani Masyarakat) di Kelurahan Ketapang Kecamatan Kademangan Kota Probolinggo memperoleh hasil konversi IKM sebesar 69,19. Kinerja unit layanan Program Demang Dimmas (Kademangan Digital Melayani Masyarakat) di Kelurahan Ketapang Kecamatan Kademangan Kota Probolinggo berada dalam mutu pelayanan "C" dengan kategori "Kurang Baik".
\end{abstract}

Kata Kunci: Indeks Kepuasan Masyaraka, Inovasi Pelayanan Publik

\footnotetext{
Kata Kunci: Indeks Kepuasan Masyaraka, Inovasi Pelayanan Publik
} 
Sawala - Jurnal Administrasi Negara

ISSN: 2598-4039 (Online)

ISSN: 2302-2221 (Print)

Volume 9 Number 2 December 2021

Page $125-140$
Copyright ( $\odot 2$ 2021, Verto Septiandika, Nur Halima. This is an open access article under the CC-BY

NC-SA license

http:// DOI 10.30656/sawala.v9i2.3420

\section{PENDAHULUAN}

Kemajuan teknologi yang semakin meningkat, serta banyaknya tuntutan masyarakat dalam berbagai jenis pelayanan yang ada, membuat pelayanan publik yang diberikan oleh unit penyelenggaraan pelayanan publik dituntut untuk memenuhi harapan masyarakat, hal tersebut perlu dilakukan karena pelayanan yang diberikan saat ini dirasakan masih belum memenuhi harapan masyarakat. Hal tersebut dapat diketahui dari banyaknya keluhan dari masyarakat, baik secara tertulis, lisan, maupun melalui media sosial. Apabila keluhan tersebut tidak mendapatkan respon yang cepat, maka akan berdampak buruk pada pemerintah dan dapat menimbulkan ketidakpercayaan dari masyarakat. Sehingga masyarakat enggan untuk mengikuti kebijakan-kebijakan pemerintah terkait dengan pelayanan publik yang disediakan oleh pemerintah. Seperti halnya ketika kita sudah memberikan keluhan mengenai kurang nyamannya fasilitas pelayanan yang diberikan, ketika kita hendak melakukan kegiatan pelayanan yang ke 2 kalinya dengan fasilitas yang masih belum berubah, makan kita enggan untuk mengurusi atau mengikuti peraturan pemerintah yang ada (Anisa 2018).

Untuk meningkatkan bagaimana inovasi tersebut dapat berkualitas dan dapat memenuhi kebutuhan masyarakat. Maka, Salah satu cara untuk meningkatkan kualitas pelayanan, yaitu mampu untuk memberikan pelayanan dengan tepat (accurately) sesuai dengan permintaan konsumen dan tanpa melakukan kesalahan setiap kali dengan kemampuan untuk dipercaya (dependably) juga disertai sikap yang baik sopan dan santun.

Dalam variabel ketetapan dan kepercayaan, perlu lebih diperhatikan sikap petugas dalam memberikan pelayanan terhadap masyarakat. Dalam hasil laporan survei kepuasan masyarakat yang dilakukan oleh Kementerian Pertahanan Republik Indonesia, walaupun frekuensinya mengalami peningkatan, yaitu $79,6 \%$ dibandingkan tahun sebelumnya yang hanya mencapai angka $77,8 \%$. Hasil ini memang masih termasuk ke dalam kategori baik, namun diharapkan kedepannya sikap petugas dalam memberikan pelayanan lebih diperbaiki lagi, agar masyarakat pengguna layanan di Kementerian Pertahanan Republik Indonesia merasakan kepuasan dalam pelayanan yang diberikan. Maka dari itu pelayanan yang diberikan oleh aparatur Kementerian Pertahanan Republik Indonesia diharapkan mengacu pada kepuasan masyarakat, karena proses penilaian suatu pelayanan yang diberikan aparatur berasal dari masyarakat, sebab masyarakat yang merasakan langsung atas layanan-layanan yang diberikan oleh Kementerian Pertahanan Republik Indonesia melalui para aparatur yang bertugas atas pelaksanaan tugas dan fungsinya (Kemeterian Pertahanan Republik Indonesia 2020).

Penelitian terdahulu tentang Indeks kepuasan masyarakat terhadap kualitas pelayanan publik. Salah satunya dengan judul "Analisis Indeks Kepuasan Masyarakat Pengguna Pelayanan Publik Pada Pemerintah Daerah di Kecamatan Pasar Muara Bungo" yang ditulis oleh Helva Rahmi, dkk (2019). Dengan hasil penelitian pengukuran indeks kepuasan masyarakat di kantor kecamatan Pasar Muara Bungo belum optimal 
Sawala - Jurnal Administrasi Negara

ISSN: 2598-4039 (Online)

ISSN: 2302-2221 (Print)

Volume 9 Number 2 December 2021

Page $125-140$
Copyright $\odot$ (2021, Verto Septiandika, Nur Halima. This is an open access article under the CC-BY

NC-SA license

http:// DOI 10.30656/sawala.v9i2.3420

dijalankan karena dapat dilihat dari unsur-unsur pelayanan yang nilainya masih ada di bawah nilai rata-rata 2,46 di antaranya ada empat unsur yang sering dikeluhkan yaitu kedisiplinan petugas pelayanan yang masih kurang baik dan kecepatan pelayanan petugas yang juga masih kurang baik, kurang bertanggung jawab dalam memberikan pelayanan serta kurang adil dalam memberikan pelayanan kepada masyarakat yang ada di kecamatan Pasar Muara Bungo (Rahmi, Rahmiati, and Dolly 2019).

Sedangkan, penelitian terdahulu lainnya yaitu dengan judul “Analisis Kepuasan Masyarakat Terhadap Pelayanan Publik Berdasarkan Indeks Kepuasan Masyarakat di Kantor Kecamatan Ayah Kabupaten Kebumen", yang ditulis oleh Indah Nur'aini Sulistyo, dkk (2020). Dengan hasil penelitian Indeks Kepuasan Masyarakat yang diberikan oleh Kantor Kecamatan Ayah Kabupaten Kebumen menggunakan 9 maka diperoleh angka indeks kepuasan masyarakat sebesar 3,29 dengan nilai konversi IKM sebesar 82,25 yang berada pada interval 76,61 - 88,30 sehingga kualitas pelayanan publik masuk dalam kategori "B". Hal ini menunjukkan bahwa kinerja unit pelayanan di Kantor Kecamatan Ayah pada tahun 2018 secara keseluruhan termasuk dalam kategori "Baik" (Sulistyo and Sotya Partiwi Ediwijoyo 2020).

Pada kota Probolinggo pelayanan publik sebelum adanya inovasi pelayanan publik, banyak terjadi masalah di tingkat kelurahan seperti diantaranya keterbatasan sarana dan prasarana, perilaku petugas yang belum bersifat melayani, ketidakpastian penyelesaian, pungli, calo, ketidakjelasan prosedur, ketidaknyamanan ruang pelayanan. Hal tersebut terjadi pada beberapa kelurahan di Kecamatan Kademangan Kota Probolinggo.

Sedangkan pada tingkat, pelayanan pegawai kelurahan terkadang masih tidak mengikuti prosedur yang ada hal ini dilihat dari proses -proses atau tahapan -tahapan yang harus dilalui dalam rangka memberikan pelayanan kepada masyarakat, yang diawali dengan menanyakan keperluan apa kepada masyarakat yang datang ke Kelurahan, namun bila masih ada masyarakat yang tidak memenuhi persyaratan yang ada seperti masyarakat yang ingin membuat KTP tidak membawa surat pengantar dari RT tempat mereka tinggal ataupun tidak membawa foto copy Kartu Keluarga yang berfungsi untuk mengetahui Nomor Induk Keluarga (N.I.K), namun pihak Kelurahan tetap memberikan pelayanannya a hal inilah yang kemudian nantinya akan menyulitkan pihak Kecamatan dalam memproses untuk di tindak lanjuti, sehingga dalam tahap akhir yaitu penandatanganan oleh Camat selaku kepala Kecamatan dan penyerahan (Linggi 2012).

Program Demang Dimmas (Kademangan Digital Melayani Masyarakat) sendiri merupakan aplikasi hasil pengembangan dari aplikasi Berkas Pelayanan Jalan Sendiri Bangkit yang merupakan hasil dari inovasi dari Kecamatan Kademangan Kota Probolinggo. Dengan sistem yang sama namun program layanan publik tersebut juga bisa di akses oleh masyarakat. Dalam aplikasi tersebut terdapat menu permohonan layanan, antrean proses surat, validasi permohonan, tentang layanan, pengaduan, berita, dan peraturan pemerintah. Program Demang Dimmas (Kademangan Digital Melayani 
Sawala - Jurnal Administrasi Negara

ISSN: 2598-4039 (Online)

ISSN: 2302-2221 (Print)

Volume 9 Number 2 December 2021

Page $125-140$
Copyright $(\subseteq 2$ 2021, Verto Septiandika, Nur Halima. This is an open access article under the CC-BY

NC-SA license http:// DOI 10.30656/sawala.v9i2.3420

Masyarakat) merupakan sistem pelayanan berbasis teknologi informasi mulai dari tingkat RT-RW-kelurahan sampai dengan kecamatan. Targetnya proses di RT RW cukup 5 menit, kelurahan 15 menit dan kecamatan 15 menit. Jadi, penyelesaian suatu dokumen cukup 35 menit. Dokumen yang sudah selesai bisa diambil ke kelurahan tanpa harus ke kecamatan. Dari hasil observasi terhadap salah satu pengguna layanan terhadap pengguna layanan Program Demang Dimmas (Kademangan Digital Melayani Masyarakat) masih di rasa kurang. Sehingga perlu adanya perbaikan kualitas pelayanan yang ada untuk memenuhi kepuasan masyarakat.

\section{TINJAUAN LITERATUR \\ Inovasi Pelayanan Publik}

Inovasi adalah proses yang berbeda untuk penemuan dan melibatkan implementasi dan / atau adaptasi pengetahuan baru. Ada tiga elemen yang terlibat - para aktor (inovator), proses (berinovasi) dan hasil (inovasi). Elemen inti yang membedakan inovasi dari perubahan inkremental adalah dampak dari penghentian dalam proses perubahan.

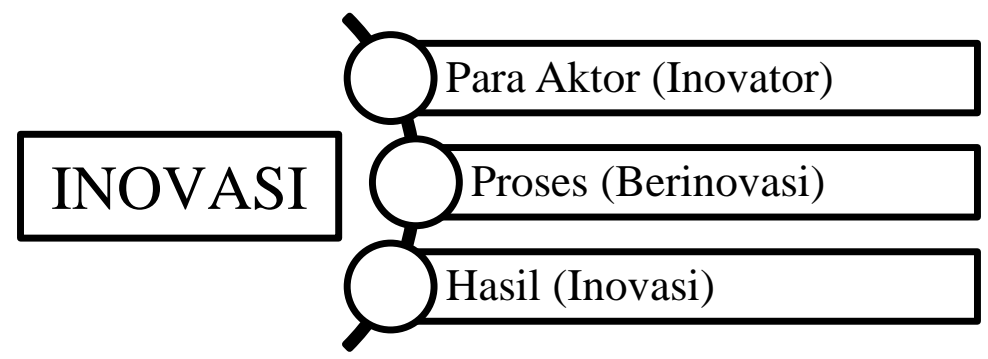

Inovasi merupakan pengenalan ke baru ke dalam sistem biasanya, tetapi tidak selalu, dalam istilah relatif dan oleh aplikasi (dan kadang-kadang penemuan) dari ide baru. Ini menghasilkan proses transformasi yang membawa penghentian dalam hal subjek itu sendiri (seperti produk atau layanan) dan / atau lingkungannya (seperti organisasi, pasar, atau komunitas) (Osborne and Brown 2012).

Pelayanan publik adalah suatu bentuk kegiatan yang diberikan kepada masyarakat umum atau penduduk negara yang diberikan dalam interaksi langsung maupun tidak langsung dengan tujuan memberikan kemudahan dan kepuasan bagi masyarakat itu sendiri (Wasistiono 2003). Pelayanan yang diberikan biasanya berupa barang maupun jasa oleh pihak instansi pemerintah baik pusat maupun daerah, atau pihak pemerintah maupun pihak swasta. Tujuan pemberian pelayanan tersebut untuk memenuhi kebutuhan masyarakat maupun dalam rangka pelaksanaan perundang-undangan (Marwiyah, Halima, and Maulidi 2020).

Masyarakat membutuhkan pelayanan untuk memenuhi berbagai macam kebutuhan yang tidak dapat dipenuhi sendiri. Pemerintah mempunyai peranan penting untuk menyediakan layanan publik sesuai yang telah diamanatkan dalam UU Nomor 25 Tahun 2009 tentang pelayanan publik (pasal 1) menyebutkan bahwa pelayanan publik sendiri 
Sawala - Jurnal Administrasi Negara

ISSN: 2598-4039 (Online)

ISSN: 2302-2221 (Print)

Volume 9 Number 2 December 2021

Page $125-140$
Copyright $\odot$ (2021, Verto Septiandika, Nur Halima. This is an open access article under the CC-BY

NC-SA license http:// DOI 10.30656/sawala.v9i2.3420

merupakan bentuk dari rangkaian suatu kegiatan yang bertujuan untuk memenuhi kebutuhan pelayanan atas barang, jasa dan/atau pelayanan administratif yang diberikan oleh aparatur negara bagi masyarakat sesuai dengan peraturan perundang-undangan. Maka, baik buruknya dari suatu mutu pelayanan publik dapat menjadi citra buruk bagi suatu pemerintahan yang berada di tengah masyarakat. Seperti halnya bagi sebagian masyarakat yang berurusan dengan birokrasi, selalu berakhir dengan mengeluh dan kecewa terhadap pelayanan yang diberikan oleh aparatur pemerintah (Mardiyanto and Ismowati 2018).

\section{Kualitas Pelayanan Publik}

Perlu diketahui bagaimana masyarakat merasa puas terhadap suatu pelayanan publik yang diberikan, dapat diketahui melalui kualitas pelayanan publik. Kualitas pelayanan publik sendiri merupakan suatu hasil dari interaksi yang di berikan dalam setiap aspek yang ada, seperti strategi, sistem pelayanan, SDM yang memberikan pelayanan, dan masyarakat yang merupakan pelanggan dari pelayanan publik itu sendiri. Sehingga Crosby, Lethimen dan Wyckoff, mendefinisikan kualitas pelayanan merupakan bentuk penyesuaian dari perincian-perincian yang ada, dimana kualitas itu sendiri dipandang sebagai derajat keunggulan yang ingin dicapai, sehingga dilakukan kontrol secara terus menerus untuk memenuhi kebutuhan pengguna jasa pelayanan publik. Maka, secara substansial kualitas pelayanan publik sendiri merupakan bentuk kesiapan dari pemberi jasa pelayanan, yang diperoleh dengan membandingkan persepsi pengguna layanan terhadap layanan yang nyata mereka terima dengan layanan yang mereka harapkan. Sehingga, apabila kenyataan yang ada sesuai dengan harapan yang diinginkan, maka pelayanan yang diberikan dapat dikatakan berkualitas. Sedangkan, apabila kenyataan tidak yang ada tidak sesuai dengan harapan yang inginkan, maka pelayanan yang diberikan dapat dikatakan berkualitas (Taufiqurokhman and Satispi 2018).

Sebagai contoh ketika seorang warga hendak melakukan kegiatan untuk mendapatkan pelayanan administrasi di instansi yang dituju, cenderung mereka mengira bahwa layanan yang akan diberikan akan mudah dan cepat namun pada kenyataannya pelayanan yang diberikan tersebut tidak sesuai dengan yang diharapkan. Dengan demikian kualitas pelayanan dapat didefinisikan seberapa jauh perbedaan antara kenyataan dengan harapan masyarakat atas pelayanan yang mereka terima.

Berdasarkan pendapat tersebut, dalam pengukuran kualitas pelayanan memiliki dua faktor, yaitu pelayanan yang diharapkan masyarakat dan kinerja pelayanan. Masyarakat mempunyai persepsi yang baik terhadap kualitas pelayanan jasa atau barang yang diberikan oleh instansi pemerintah maupun swasta, maka penyedia layanan dapat mengetahui apa saja yang menjadi harapan masyarakat terhadap pelayanan yang dibutuhkan. Sehingga, tidak terjadi perbedaan antara harapan masyarakat dengan 
Sawala - Jurnal Administrasi Negara

ISSN: 2598-4039 (Online)

ISSN: 2302-2221 (Print)

Volume 9 Number 2 December 2021

Page 125 - 140
Copyright $@$ 2021, Verto Septiandika, Nur Halima. This is an open access article under the CC-BY

NC-SA license http:// DOI 10.30656/sawala.v9i2.3420

kinerja pelayanan yang berikan, yang akhirnya dapat membuat merasa puas terhadap kualitas pelayanan publik yang diterima.

\section{Kepuasan Masyarakat Terhadap Pelayanan Publik}

Seseorang akan merasa puas dapat dilihat dari nilai pelayanan jasa atau produk yang diberikan oleh suatu instansi baik pemerintah maupun swasta. Tingkat kepuasan seseorang dapat ditentukan oleh berbagai faktor-faktor yang menjadi bagian dari kualitas pelayanan yang diberikan. Masyarakat sendiri memiliki banyak kebutuhan baik terhadap jasa maupun barang yang didasarkan dari beberapa karakteristik. Karakteristik tersebut merupakan bagian dari harapan masyarakat. Pemenuhan harapan masyarakat sendiri menjadi tugas dari penyelenggara pelayanan dalam memberikan jasa atau barang, dengan memberikan pelayanan yang terbaik. Parasuraman mengidentifikasi sepuluh dimensi kualitas (Fandy and Gregorius 2005), yaitu:

a) Reliability, mencangkup dua hal pokok, yaitu konsistensi kerja (performance) dan kemampuan untuk dipercaya (dependability). Hal tersebut dapat diartikan instansi pemberi jasa layanan mampu dipercaya dan dapat memberikan jasanya secara tepat semenjak saat pertama (right the first time).

b) Responsiveness, merupakan kesiapan atau kemauan dari para aparatur atau karyawan dalam memberikan pelayanan baik jasa maupun barang yang dibutuhkan masyarakat.

c) Competence, artinya setiap sumber daya manusia yang berada di dalam instansi memiliki pengetahuan dan keterampilan yang memadai agar dapat memberikan pelayanan jasa maupun barang kepada masyarakat.

d) Access, meliputi kemudahan untuk ditemui dan dihubungi, sehingga masyarakat dapat dengan mudah mendapatkan pelayanan jasa maupun barang yang dibutuhkan oleh masyarakat.

e) Courtesy, meliputi merupakan sikap dari para karyawan seperti sikap sopan santun, respek, perhatian, dan keramahan yang dimiliki para contact personnel, hal tersebut dapat memberikan kenyamanan bagi masyarakat ketika hendak melakukan kegiatan pelayanan publik.

f) Communication, artinya komunikasi yang terjadi di dalam proses pelayanan, seperti kegiatan memberikan informasi kepada masyarakat dalam bahasa yang mereka pahami, serta selalu mendengarkan saran dan keluhan masyarakat.

g) Credibility, yaitu bentuk dari kepercayaan dan sifat jujur yang ada pada instansi pemberi pelayanan publik. Kredibilitas yang diberikan bersangkutan dengan reputasi instansi, nama instansi, interaksi masyarakat, dan karakteristik pribadi contact personnel.

h) Security, merupakan keamanan dari bahaya, risiko, atau keragu-raguan terhadap data yang diberikan kepada pihak instansi penyelenggara pelayanan publik. Aspek 
Sawala - Jurnal Administrasi Negara ISSN: 2598-4039 (Online)

ISSN: 2302-2221 (Print)

Volume 9 Number 2 December 2021

Page $125-140$
Copyright $@$ 2021, Verto Septiandika, Nur Halima. This is an open access article under the CC-BY

NC-SA license http:// DOI 10.30656/sawala.v9i2.3420

tersebut meliputi keamanan secara fisik (physical safety), keamanan finansial (financial security), dan kerahasiaan (confidentiality).

i) Understanding/Knowing the Customer, merupakan usaha untuk memahami kebutuhan masyarakat yang diberikan oleh pihak instansi pemberi pelayanan.

j) Tangibles, merupakan salah satu bukti fisik dari jasa, bisa berupa fasilitas fisik yang merupakan bagian dari pelayanan publik, seperti peralatan yang dipergunakan, representasi fisik dari jasa.

\section{METODOLOGI}

Dalam penelitian ini metode yang digunakan adalah deskriptif kuantitatif, sesuai dengan rumusan masalah yang bersifat deskriptif. Penelitian ini menggunakan data kuantitatif yang dilakukan dengan menggunakan nilai Indeks Kepuasan Masyarakat (IKM) yang dihitung dengan menggunakan nilai rata-rata tertimbang masing-masing unsur pelayanan. Dalam perhitungan Indeks Kepuasan Masyarakat (IKM) terdapat 10 unsur yang dikaji. Setiap unsur pelayanan mempunyai penimbangan yang sama dengan rumus sebagai berikut:

$$
\text { Bobot nilai rata }- \text { rata tertimbang }=\frac{\text { Jumlah bobot }}{\text { Jumlah unsur }}=\frac{1}{10}=0,1
$$

Untuk memperoleh nilai Indeks Kepuasan Masyarakat (IKM) dipergunakan rumus sebagai berikut:

Indeks Kepuasan Masyarakat (IKM)

$$
=\frac{\text { Total dari nilai persepsi per unsur }}{\text { Total unsur yang terisi }} \times \text { nilai penimbang }
$$

Keterangan:

Nilai persepsi per unsur $=$ Nilai dari jawaban responden atas 10 unsur

Total unsur yang terisi = Jumlah unsur yang dijawab responden

Nilai penimbang = bobot nilai rat-rata tertimbang

Untuk mempermudah interpretasi terhadap penilaian Indeks Kepuasan Masyarakat (IKM) yaitu antar 25-100, maka hasil penilaian tersebut diatas dikonversikan dengan nilai dasar 25 dengan rumus sebagai berikut:

\section{Indeks Kepuasan Masyarakat (IKM) Unit Pelayan X 25}

Kemudian hasil perhitungan tersebut diatas dikategorikan sebagai berikut: 
Sawala - Jurnal Administrasi Negara

ISSN: 2598-4039 (Online)

ISSN: 2302-2221 (Print)

Volume 9 Number 2 December 2021

Page $125-140$
Copyright $(\subseteq 2$ 2021, Verto Septiandika, Nur Halima. This is an open access article under the CC-BY

NC-SA license http:// DOI 10.30656/sawala.v9i2.3420

Tabel Nilai Persepsi, Interval Indeks Kepuasan Masyarakat (IKM), dan Interval Konversi Indeks Kepuasan Masyarakat (IKM)

\begin{tabular}{ccccc}
\hline \hline No & Nilai interval & $\begin{array}{c}\text { Konversi } \\
\text { IKM }\end{array}$ & $\begin{array}{c}\text { Mutu } \\
\text { Pelayanan }\end{array}$ & $\begin{array}{c}\text { Kinerja unit } \\
\text { Pelayanan }\end{array}$ \\
\hline \hline 1. & $1,00-2,5996$ & $25,00-64,99$ & D & Tidak Baik \\
2. & $2,60-3,064$ & $65,00-76,60$ & C & Kurang Baik \\
3. & $3,0664-3,532$ & $76,61-88,30$ & B & Baik \\
4. & $3,5324-4,00$ & $88,31-100,00$ & A & Sangat Baik \\
\hline \hline
\end{tabular}

Sumber : (Siyoto 2015)

Dari tabel diatas kemudian dapat menyimpulkan seberapa besar Indeks Kepuasan Masyarakat (IKM) Pengguna Layanan Program Demang Dimmas (Kademangan Digital Melayani Masyarakat) di Kelurahan Ketapang Kecamatan Kademangan Kota Probolinggo. Dalam penelitian ini menghasilkan data berupa gambaran dengan kalimatkalimat mengenai kepuasan masyarakat terhadap kualitas pelayanan publik. Sehingga penelitian ini menggunakan analisis Indeks Kepuasan Masyarakat (IKM). Data yang terkumpul dalam bentuk angka-angka kemudian akan dihitung sesuai dengan ketentuan penghitungan Indeks Kepuasan Masyarakat (IKM), yang selanjutnya ditafsirkan dalam kalimat-kalimat.

Besarnya populasi dalam penelitian dan mempertimbangkan faktor-faktor yang menunjang keberhasilan pelaksanaan penelitian maka dalam penelitian ini dilakukan sampling. Teknik sampling yang digunakan dalam penelitian ini adalah teknik nonprobability sampling dengan jenis accidental sampling, yaitu teknik penentuan sampel berdasarkan faktor spontanitas, artinya siapa saja yang secara tidak sengaja bertemu dengan peneliti dan sesuai dengan karakteristik atau ciri-cirinya yaitu masyarakat yang menjadi pengguna layanan Program Demang Dimmas (Kademangan Digital Melayani Masyarakat) di Kelurahan Ketapang Kecamatan Kademangan Kota Probolinggo, maka orang tersebut dapat digunakan sebagai sampel (responden) sebagai dasar pengumpulan data. Sampel penelitian ditargetkan berjumlah 100 responden sesuai dengan jumlah minimal responden dalam penyusunan Indeks Kepuasan Masyarakat yang dipilih secara tidak sengaja.

\section{HASIL DAN PEMBAHASAN}

1. Hasil Indeks Kepuasan Masyarakat terhadap kualitas layanan Program Demang Dimmas (Kademangan Digital Melayani Masyarakat) di Kelurahan Ketapang Kecamatan Kademangan Kota Probolinggo

Kepuasan masyarakat dapat diketahui dengan melihat kualitas pelayanan publik yang telah diberikan dari masing-masing unsur yang telah ditentukan. Adapun unsur atau dimensi kepuasan masyarakat yaitu Reability, Responsiveness, Competence, Acces, Courtesy, Communication, Credibility, Security, Understanding, dan Tangible. Berdasarkan 
Sawala - Jurnal Administrasi Negara ISSN: 2598-4039 (Online)

ISSN: 2302-2221 (Print)

Volume 9 Number 2 December 2021

Page $125-140$
Copyright $\left(C_{2021}\right.$, Verto Septiandika, Nur Halima. This is an open access article under the CC-BY

NC-SA license http:// DOI 10.30656/sawala.v9i2.3420

perhitungan Indeks Kepuasan Masyarakat menggunakan Microsoft Exel 2010, diperoleh hasil statistik mengenai analisis kepuasan masyarakat terhadap kualitas layanan Program Demang Dimmas (Kademangan Digital Melayani Masyarakat) di Kelurahan Ketapang Kecamatan Kademangan Kota Probolinggo yang disajikan dalam tabel berikut:

Tabel Hasil Kuesioner dan Prosentase Penilaian Setiap Unsur Pelayanan

\begin{tabular}{|c|c|c|c|c|c|}
\hline No & Unsur & Rata-rata & $\begin{array}{c}\text { Prosentase } \\
\text { penilaian }\end{array}$ & $\begin{array}{c}\text { Mutu } \\
\text { pelayanan }\end{array}$ & Keterangan \\
\hline 1. & Reability & 13,92 & 69,6 & $\mathrm{C}$ & Kurang Baik \\
\hline 2. & Responsiveness & 11,05 & 69,06 & $\mathrm{C}$ & Kurang Baik \\
\hline 3. & Competence & 2,69 & 67,25 & $\mathrm{C}$ & Kurang Baik \\
\hline 4. & Acces & 2,73 & 68,25 & C & Kurang Baik \\
\hline 5. & Coutesy & 2,85 & 71,25 & $\mathrm{C}$ & Kurang Baik \\
\hline 6. & Communication & 2,78 & 69,5 & $\mathrm{C}$ & Kurang Baik \\
\hline 7. & Credibility & 2,76 & 69 & $\mathrm{C}$ & Kurang Baik \\
\hline 8. & Security & 2,81 & 71,75 & $\mathrm{C}$ & Kurang Baik \\
\hline 9. & Understanding & 8,25 & 68,75 & $\mathrm{C}$ & Kurang Baik \\
\hline \multirow[t]{5}{*}{10} & Tangible & 11,67 & 72,93 & C & Kurang Baik \\
\hline & Bobot & 1 & & & \\
\hline & Unsur & 22 & & & \\
\hline & $\begin{array}{ll}\text { Bobot NRR } \\
\text { Tertimbang }\end{array}$ & 0,045 & & & \\
\hline & $\mathrm{n}$ Responden & 100 & & & \\
\hline
\end{tabular}

Sumber: Peneliti, 2021

\section{Prosentase Penilaian}

$\begin{array}{lllllllllll}64 & 65 & 66 & 67 & 68 & 69 & 70 & 71 & 72 & 73 & 74\end{array}$

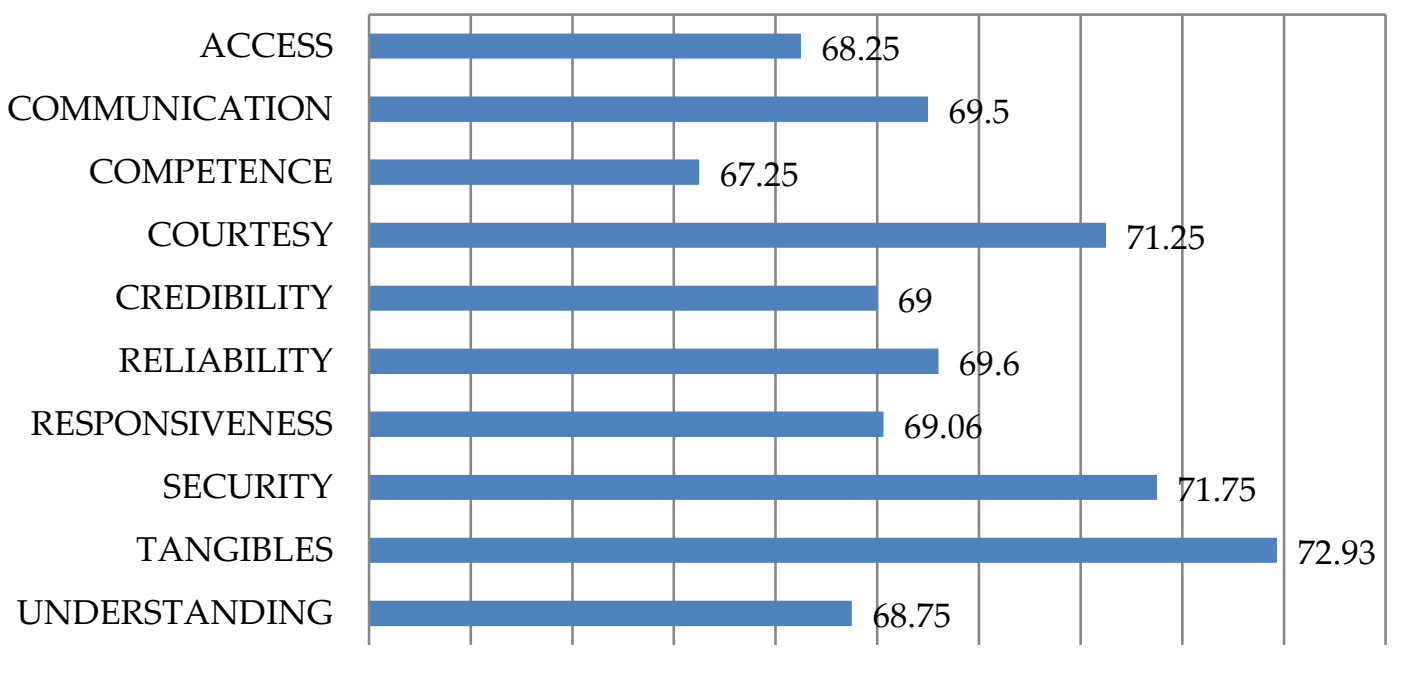

Gambar Grafik Prosentase Penilaian setiap Unsur Pelayanan

Sumber: Peneliti, 2021 
Sawala - Jurnal Administrasi Negara

ISSN: 2598-4039 (Online)

ISSN: 2302-2221 (Print)

Volume 9 Number 2 December 2021

Page $125-140$
Copyright $(\odot)$ 2021, Verto Septiandika, Nur Halima. This is an open access article under the CC-BY

NC-SA license http:// DOI 10.30656/sawala.v9i2.3420

Hasil penelitian menunjukkan bahwa Kinerja unit layanan Program Demang Dimmas (Kademangan Digital Melayani Masyarakat) di Kelurahan Ketapang Kecamatan Kademangan Kota Probolinggo berada dalam mutu pelayanan "C" dengan kategori "Kurang Baik". Hal ini ditunjukkan dengan nilai Indeks Kepuasan Masyarakat (IKM) dari 10 (sepuluh) unsur IKM sebesar 2,76 dan dengan nilai konversi IKM sebesar 69,19 . Indikator yang memiliki nilai IKM tertinggi adalah Tangible dengan nilai IKM sebesar 11,67 dengan nilai konversi IKM sebesar 72,93. Sedangkan indikator yang memiliki nilai IKM terendah adalah indikator Competence mendapatkan nilai IKM sebesar 2,69 dan nilai konversi IKM sebesar 67,25.

\section{A. Reliability layanan Program Demang Dimmas (Kademangan Digital Melayani Masyarakat) di Kelurahan Ketapang}

Reliability layanan Program Demang Dimmas (Kademangan Digital Melayani Masyarakat) di Kelurahan Ketapang mencangkup dua hal pokok, yaitu konsistensi kerja (performance) dan kemampuan untuk dipercaya (dependability). Hal ini berarti instansi memberikan jasanya secara tepat semenjak saat pertama (right the first time). Selain itu juga berarti bahwa instansi yang bersangkutan memenuhi janjinya. Berdasarkan hasil penelitian di atas bahwa Reliability layanan Program Demang Dimmas (Kademangan Digital Melayani Masyarakat) di Kelurahan Ketapang Kecamatan Kademangan Kota Probolinggo memiliki mutu pelayanan "C" dengan kategori "Kurang Baik". Hal tersebut dapat dilihat dari nilai Indeks Kepuasan Masyarakat (IKM) untuk Reliability (Keandalan) sebesar 13,92 dengan nilai konversi IKM sebesar 69,6. Masyarakat merasa konsistensi kerja (performance) dan kemampuan untuk dipercaya (dependability) dalam penggunaan layanan Program Demang Dimmas (Kademangan Digital Melayani Masyarakat) masih kurang baik. Hal tersebut perlu dilakukan upaya untuk meningkatkan Reliability (Keandalan) layanan Program Demang Dimmas (Kademangan Digital Melayani Masyarakat) di Kelurahan Ketapang.

\section{B. Responsiveness layanan Program Demang Dimmas (Kademangan Digital Melayani Masyarakat) di Kelurahan Ketapang}

Responsiveness layanan Program Demang Dimmas (Kademangan Digital Melayani Masyarakat) di Kelurahan Ketapang dijabarkan dengan kemauan atau kesiapan para karyawan untuk memberikan jasa yang dibutuhkan masyarakat. Berdasarkan hasil penelitian di atas bahwa Responsiveness layanan Program Demang Dimmas (Kademangan Digital Melayani Masyarakat) di Kelurahan Ketapang Kecamatan Kademangan Kota Probolinggo memiliki mutu pelayanan "C" dengan kategori "Kurang Baik". Hal tersebut dapat dilihat dari nilai Indeks Kepuasan Masyarakat (IKM) untuk Responsiveness (respon) sebesar 11,05 dengan nilai konversi IKM sebesar 69,06. Masyarakat merasa kemauan atau kesiapan para karyawan untuk 
Sawala - Jurnal Administrasi Negara

ISSN: 2598-4039 (Online)

ISSN: 2302-2221 (Print)

Volume 9 Number 2 December 2021

Page $125-140$
Copyright $\odot$ (2021, Verto Septiandika, Nur Halima. This is an open access article under the CC-BY

NC-SA license http:// DOI 10.30656/sawala.v9i2.3420

memberikan jasa yang dibutuhkan masyarakat dalam penggunaan layanan Program Demang Dimmas (Kademangan Digital Melayani Masyarakat) masih kurang baik. Hal tersebut perlu dilakukan upaya untuk meningkatkan Responsiveness (respon) layanan Program Demang Dimmas di Kelurahan Ketapang.

\section{Competence layanan Program Demang Dimmas (Kademangan Digital Melayani Masyarakat) di Kelurahan Ketapang}

Competence layanan Program Demang Dimmas (Kademangan Digital Melayani Masyarakat) di Kelurahan Ketapang dijabarkan dengan setiap orang dalam suatu instansi memiliki keterampilan dan pengetahuan yang dibutuhkan agar dapat memberikan jasa tertentu. Berdasarkan hasil penelitian di atas bahwa Competence layanan Program Demang Dimmas (Kademangan Digital Melayani Masyarakat) di Kelurahan Ketapang Kecamatan Kademangan Kota Probolinggo memiliki mutu pelayanan "C" dengan kategori "Kurang Baik". Hal tersebut dapat dilihat dari nilai Indeks Kepuasan Masyarakat (IKM) untuk Competence (Kompetensi) sebesar 2,69 dengan nilai konversi IKM sebesar 67,25. Masyarakat merasa setiap orang dalam suatu instansi memiliki keterampilan dan pengetahuan yang dibutuhkan agar dapat memberikan jasa tertentu dalam penggunaan layanan Program Demang Dimmas (Kademangan Digital Melayani Masyarakat) masih kurang baik. Hal tersebut perlu dilakukan upaya untuk meningkatkan Competence (Kompetensi) layanan Program Demang Dimmas (Kademangan Digital Melayani Masyarakat) di Kelurahan Ketapang.

\section{Access layanan Program Demang Dimmas (Kademangan Digital Melayani Masyarakat) di Kelurahan Ketapang}

Access layanan Program Demang Dimmas (Kademangan Digital Melayani Masyarakat) di Kelurahan Ketapang dijabarkan dengan kemudahan untuk dihubungi dan ditemui. Hal ini berarti lokasi fasilitas jasa yang mudah dijangkau, waktu menunggu yang tidak terlalu lama, saluran komunikasi instansi mudah dihubungi, dan lain-lain. Berdasarkan hasil penelitian di atas bahwa Access layanan Program Demang Dimmas (Kademangan Digital Melayani Masyarakat) di Kelurahan Ketapang Kecamatan Kademangan Kota Probolinggo memiliki mutu pelayanan "C" dengan kategori "Kurang Baik". Hal tersebut dapat dilihat dari nilai Indeks Kepuasan Masyarakat (IKM) untuk Access (Akses) sebesar 2,73 dengan nilai konversi IKM sebesar 68,25. Masyarakat merasa lokasi fasilitas jasa yang mudah dijangkau, waktu menunggu yang tidak terlalu lama, saluran komunikasi instansi mudah dihubungi, dan lain-lain dalam penggunaan layanan Program Demang Dimmas (Kademangan Digital Melayani Masyarakat) masih kurang baik. Hal tersebut perlu dilakukan upaya untuk meningkatkan Access (Akses) layanan Program Demang Dimmas di Kelurahan Ketapang. 
Sawala - Jurnal Administrasi Negara

ISSN: 2598-4039 (Online)

ISSN: 2302-2221 (Print)

Volume 9 Number 2 December 2021

Page $125-140$
Copyright $@$ 2021, Verto Septiandika, Nur Halima. This is an open access article under the CC-BY

NC-SA license http:// DOI 10.30656/sawala.v9i2.3420

\section{E. Courtesy layanan Program Demang Dimmas (Kademangan Digital Melayani Masyarakat) di Kelurahan Ketapang}

Courtesy layanan Program Demang Dimmas (Kademangan Digital Melayani Masyarakat) di Kelurahan Ketapang dijabarkan dengan sikap sopan santun, respek, perhatian, dan keramahan yang dimiliki para contact personnel. Berdasarkan hasil penelitian di atas bahwa Courtesy layanan Program Demang Dimmas (Kademangan Digital Melayani Masyarakat) di Kelurahan Ketapang Kecamatan Kademangan Kota Probolinggo memiliki mutu pelayanan " $\mathrm{C}$ " dengan kategori "Kurang Baik". Hal tersebut dapat dilihat dari nilai Indeks Kepuasan Masyarakat (IKM) untuk Courtesy (Sopan Santun) sebesar 2,85 dengan nilai konversi IKM sebesar 71,25. Masyarakat merasa sikap sopan santun, respek, perhatian, dan keramahan yang dimiliki para contact personnel dalam penggunaan layanan Program Demang Dimmas (Kademangan Digital Melayani Masyarakat) masih kurang baik. Hal tersebut perlu dilakukan upaya untuk meningkatkan Courtesy (Sopan Santun) layanan Program Demang Dimmas (Kademangan Digital Melayani Masyarakat) di Kelurahan Ketapang.

\section{F. Communication layanan Program Demang Dimmas (Kademangan Digital Melayani Masyarakat) di Kelurahan Ketapang}

Communication layanan Program Demang Dimmas (Kademangan Digital Melayani Masyarakat) di Kelurahan Ketapang dijabarkan dengan memberikan informasi kepada masyarakat dalam bahasa yang mereka pahami, serta selalu mendengarkan saran dan keluhan masyarakat. Berdasarkan hasil penelitian di atas bahwa Communication layanan Program Demang Dimmas (Kademangan Digital Melayani Masyarakat) di Kelurahan Ketapang Kecamatan Kademangan Kota Probolinggo memiliki mutu pelayanan "C" dengan kategori "Kurang Baik". Hal tersebut dapat dilihat dari nilai Indeks Kepuasan Masyarakat (IKM) untuk Communication (Komunikasi) sebesar 2,78 dengan nilai konversi IKM sebesar 69,5. Masyarakat merasa memberikan informasi kepada masyarakat dalam bahasa yang mereka pahami, serta selalu mendengarkan saran dan keluhan masyarakat dalam penggunaan layanan Program Demang Dimmas (Kademangan Digital Melayani Masyarakat) masih kurang baik. Hal tersebut perlu dilakukan upaya untuk meningkatkan Communication (Komunikasi) layanan Program Demang Dimmas (Kademangan Digital Melayani Masyarakat) di Kelurahan Ketapang.

\section{G. Credibility layanan Program Demang Dimmas (Kademangan Digital Melayani} Masyarakat) di Kelurahan Ketapang

Credibility layanan Program Demang Dimmas (Kademangan Digital Melayani Masyarakat) di Kelurahan Ketapang dijabarkan dengan sifat jujur dan dapat dipercaya. Kredibilitas mencangkup nama perusahaan, reputasi instansi, 
Sawala - Jurnal Administrasi Negara

ISSN: 2598-4039 (Online)

ISSN: 2302-2221 (Print)

Volume 9 Number 2 December 2021

Page $125-140$
Copyright $(\odot)$ 2021, Verto Septiandika, Nur Halima. This is an open access article under the CC-BY

NC-SA license http:// DOI 10.30656/sawala.v9i2.3420

karakteristik pribadi contact personnel, dan interaksi masyarakat. Berdasarkan hasil penelitian di atas bahwa Credibility layanan Program Demang Dimmas (Kademangan Digital Melayani Masyarakat) di Kelurahan Ketapang Kecamatan Kademangan Kota Probolinggo memiliki mutu pelayanan "C" dengan kategori "Kurang Baik". Hal tersebut dapat dilihat dari nilai Indeks Kepuasan Masyarakat (IKM) untuk Credibility (Kredibilitas) sebesar 2,76 dengan nilai konversi IKM sebesar 69. Masyarakat merasa sifat jujur dan dapat dipercaya. Kredibilitas mencangkup nama perusahaan, reputasi instansi, karakteristik pribadi contact personnel, dan interaksi masyarakat dalam penggunaan layanan Program Demang Dimmas (Kademangan Digital Melayani Masyarakat) masih kurang baik. Hal tersebut perlu dilakukan upaya untuk meningkatkan Credibility (Kredibilitas) layanan Program Demang Dimmas (Kademangan Digital Melayani Masyarakat) di Kelurahan Ketapang.

\section{H. Security layanan Program Demang Dimmas (Kademangan Digital Melayani Masyarakat) di Kelurahan Ketapang}

security layanan Program Demang Dimmas (Kademangan Digital Melayani Masyarakat) di Kelurahan Ketapang dijabarkan dengan aman dari bahaya, risiko, atau keragu-raguan. Berdasarkan hasil penelitian di atas bahwa Security layanan Program Demang Dimmas (Kademangan Digital Melayani Masyarakat) di Kelurahan Ketapang Kecamatan Kademangan Kota Probolinggo memiliki mutu pelayanan "C" dengan kategori "Kurang Baik". Hal tersebut dapat dilihat dari nilai Indeks Kepuasan Masyarakat (IKM) untuk Security (Keamanan) sebesar 2,81 dengan nilai konversi IKM sebesar 71,75. Masyarakat merasa aman dari bahaya, risiko, atau keragu-raguan dalam penggunaan layanan Program Demang Dimmas (Kademangan Digital Melayani Masyarakat) masih kurang baik. Hal tersebut perlu dilakukan upaya untuk meningkatkan Security (Keamanan) layanan Program Demang Dimmas (Kademangan Digital Melayani Masyarakat) di Kelurahan Ketapang.

I. Understanding/Knowing the customer layanan Program Demang Dimmas (Kademangan Digital Melayani Masyarakat) di Kelurahan Ketapang

Understanding/Knowing the customer layanan Program Demang Dimmas (Kademangan Digital Melayani Masyarakat) di Kelurahan Ketapang dijabarkan dengan usaha untuk memahami kebutuhan masyarakat, dan lain-lain. Berdasarkan hasil penelitian di atas bahwa Understanding layanan Program Demang Dimmas (Kademangan Digital Melayani Masyarakat) di Kelurahan Ketapang Kecamatan Kademangan Kota Probolinggo memiliki mutu pelayanan "C" dengan kategori "Kurang Baik". Hal tersebut dapat dilihat dari nilai Indeks Kepuasan Masyarakat (IKM) untuk Understanding/Knowing the customer (Memahami/Pengetahuan 
Sawala - Jurnal Administrasi Negara

ISSN: 2598-4039 (Online)

ISSN: 2302-2221 (Print)

Volume 9 Number 2 December 2021

Page $125-140$
Copyright $\odot$ (2021, Verto Septiandika, Nur Halima. This is an open access article under the CC-BY

NC-SA license http:// DOI 10.30656/sawala.v9i2.3420

Pelanggan) sebesar 8,25 dengan nilai konversi IKM sebesar 68,75. Masyarakat merasa usaha untuk memahami kebutuhan masyarakat dalam penggunaan layanan Program Demang Dimmas (Kademangan Digital Melayani Masyarakat) masih kurang baik. Hal tersebut perlu dilakukan upaya untuk meningkatkan Understanding/Knowing the customer (Memahami/Pengetahuan Pelanggan) layanan Program Demang Dimmas (Kademangan Digital Melayani Masyarakat) di Kelurahan Ketapang.

\section{J. Tangible layanan Program Demang Dimmas (Kademangan Digital Melayani Masyarakat) di Kelurahan Ketapang}

Tangible layanan Program Demang Dimmas (Kademangan Digital Melayani Masyarakat) di Kelurahan Ketapang dijabarkan dengan bukti fisik dari jasa, bisa berupa fasilitas fisik, peralatan yang dipergunakan, representasi fisik dari jasa. Berdasarkan hasil penelitian di atas bahwa Tangible layanan Program Demang Dimmas (Kademangan Digital Melayani Masyarakat) di Kelurahan Ketapang Kecamatan Kademangan Kota Probolinggo memiliki mutu pelayanan "C" dengan kategori "Kurang Baik". Hal tersebut dapat dilihat dari nilai Indeks Kepuasan Masyarakat (IKM) untuk Tangible (Berwujud) sebesar 11,67 dengan nilai konversi IKM sebesar 72,93. Masyarakat merasa bukti fisik dari jasa, bisa berupa fasilitas fisik, peralatan yang dipergunakan, representasi fisik dari jasa dalam penggunaan layanan Program Demang Dimmas (Kademangan Digital Melayani Masyarakat) masih kurang baik. Hal tersebut perlu dilakukan upaya untuk meningkatkan Tangible (Berwujud) layanan Program Demang Dimmas (Kademangan Digital Melayani Masyarakat) di Kelurahan Ketapang.

Unsur pelayanan tersebut dapat menjelaskan mengapa bahwa Kinerja unit layanan Program Demang Dimmas (Kademangan Digital Melayani Masyarakat) di Kelurahan Ketapang Kecamatan Kademangan Kota Probolinggo mendapatkan penilaian kurang baik, atau mendapatkan nilai yang kurang memuaskan. Perlu dipahami terlebih dahulu, penggunaan layanan baik secara online memiliki sisi kelebihan dan kelemahan. Pada sisi kelebihan prosedur layanan menjadi mudah, cepat, efektif, dan sederhana. Akan tetapi kekurangan yang ada adalah masyarakat masih belum terbiasa, dan masyarakat belum tentu mengetahui betul setiap prosedur pelayanan yang ada.

Unit layanan Program Demang Dimmas (Kademangan Digital Melayani Masyarakat) di Kelurahan Ketapang Kecamatan Kademangan Kota Probolinggo masyarakat sendiri memiliki kekurangan seperti ketika warga hendak melakukan akses atau login dalam aplikasi pelayanan tersebut mengalami kendala. Padahal telah melakukan register sesuai data yang diberikan. Sehingga pada akhirnya tidak banyak masyarakat yang mengerti akan aplikasi program tersebut. Selain itu juga program tersebut tidak dapat diproses oleh masyarakat langsung, masih memalui RT (Rukun 
Sawala - Jurnal Administrasi Negara

ISSN: 2598-4039 (Online)

ISSN: 2302-2221 (Print)

Volume 9 Number 2 December 2021

Page $125-140$
Copyright $(\subseteq 2$ 2021, Verto Septiandika, Nur Halima. This is an open access article under the CC-BY

NC-SA license http:// DOI 10.30656/sawala.v9i2.3420

Tetangga) dan RW (Rukun Warga) untuk memproses pelayanan. Namun Program Demang Dimmas (Kademangan Digital Melayani Masyarakat) sendiri memilki kelebihan yaitu kita dapat mengetahui pelayanan administrasi apa saja yang dapat diberikan oleh Kelurahan Ketapang Kecamatan Kademangan dan dapat mengetahui persyaratan, cara pendaftaran, dasar hukum, waktu, dan jangka waktu yang diberikan.

Dari kelebihan dan kekurangan tersebut, sudah dapat diketahui program tersebut masih perlu ditingkatkan kembali, agar tingkat kepuasan masyarakat terhadap layanan Program Demang Dimmas (Kademangan Digital Melayani Masyarakat) di Kelurahan Ketapang Kecamatan Kademangan Kota Probolinggo dapat terus meningkat. Karena program tersebut juga merupakan inovasi pelayanan yang baik. Sehingga, dimensi kepuasan masyarakat yaitu Reliability, Responsiveness, Competence, Access, Courtesy, Communication, Credibility, Security, Understanding, dan Tangible, dapat terus membaik.

\section{PENUTUP}

\section{Kesimpulan}

Berdasarkan perhitungan Indeks Kepuasan Masyarakat, maka kualitas layanan Program Demang Dimmas (Kademangan Digital Melayani Masyarakat) di Kelurahan Ketapang Kecamatan Kademangan Kota Probolinggo memperoleh hasil konversi IKM sebesar 69,19. Kinerja unit layanan Program Demang Dimmas (Kademangan Digital Melayani Masyarakat) di Kelurahan Ketapang Kecamatan Kademangan Kota Probolinggo berada dalam mutu pelayanan "C" dengan kategori "Kurang Baik".

Berdasarkan 10 (sepuluh) unsur IKM sebesar 2,76 dan dengan nilai konversi IKM sebesar 69,19. Indikator yang memiliki nilai IKM tertinggi adalah Tangible dengan nilai IKM sebesar 11,67 dengan nilai konversi IKM sebesar 72,93. Sedangkan indikator yang memiliki nilai IKM terendah adalah indikator Responsiveness mendapatkan nilai IKM sebesar 11,05 dan nilai konversi IKM sebesar 69,06.

\section{Saran}

1. Pelayanan Program Demang Dimmas (Kademangan Digital Melayani Masyarakat) di Kelurahan Ketapang Kecamatan Kademangan Kota Probolinggo tergolong kurang baik. Untuk kedepannya maka, perlu mengoptimalkan kembali Program Demang Dimmas (Kademangan Digital Melayani Masyarakat) dan perlu ditingkatkan kembali pelayanan yang diberikan agar menjadi lebih baik lagi.

2. Unsur Reliability, Responsiveness, Competence, Access, Courtesy, Communication, Credibility, Security, Understanding/Knowing the customer, dan Tangible yang ada perlu ditingkatkan kembali dengan memperbaiki tingkat kecepatan pelayanan yang diberikan dan memberikan informasi pelayanan yang jelas kepada setiap masyarakat, sehingga pihak Kelurahan Ketapang Kecamatan Kademangan Kota Probolinggo dapat memberikan pelayanan yang mudah, cepat, dan aman. 
Sawala - Jurnal Administrasi Negara

ISSN: 2598-4039 (Online)

ISSN: 2302-2221 (Print)

Volume 9 Number 2 December 2021

Page $125-140$
Copyright $@$ 2021, Verto Septiandika, Nur Halima. This is an open access article under the CC-BY

NC-SA license http:// DOI 10.30656/sawala.v9i2.3420

3. Maka, peneliti mengemukakan saran kepada pihak Kelurahan Ketapang Kecamatan Kademangan Kota Probolinggo kedepannya perlu adanya pembenahan dalam sistem dan petugas, dan harus selalu memperhatikan apa saja yang sedang dibutuhkan masyarakat. Dan semoga kedepannya jika pelayanan di Kelurahan Ketapang Kecamatan Kademangan Kota Probolinggo dapat ditingkatkan lagi. Maka, kepuasan masyarakat akan pelayanan di Kelurahan Ketapang Kecamatan Kademangan Kota Probolinggo pun akan mencapai tingkat yang maksimal.

\section{REFERENSI}

Anisa, Siti. 2018. Pengaruh Pelayanan Publik Terhadap Kepuasan Masyarakat Di Kantor Desa Helvetia. Medan: Fakultas Ekonomi dan Bisnis Islam Universitas Islam Negeri Sumatera Utara Medan.

Fandy, Tjiptono, and Chandra Gregorius. 2005. Service, Quality E Satisfaction. Yogyakarta: Andi Offset.

Kemeterian Pertahanan Republik Indonesia. 2020. Laporan Survei Kepuasan Masyarakat. Jakarta: Kementerian Pertahanan Republik Indonesia.

Linggi, Rita Kala. 2012. "Pelayanan Aparatur Kelurahan Kepada Masyarakat Di Kelurahan Sempaja Selatan Kota Samarinda." Jurnal Paradigma 1(3):324-35.

Mardiyanto, Rizka, and Mary Ismowati. 2018. “Analisis Indeks Kepuasan Masyarakat Dalam Upaya Peningkatan Kepuasan Kualitas Pelayanan Masyarakat Di Kantor Kecamatan Kotabaru Kabupaten Karawang." Transparansi Jurnal Ilmiah Ilmu Administrasi 9(2):184-97.

Marwiyah, Siti, Nur Halima, and Finni Maulidi. 2020. “Analisis Tipe Kepemimpinan

Paternalistik Dalam Peningkatan Pelayanan Publik Di Tengah Situasi Pandemik Covid-19." Jurnal Inovasi Ilmu Sosial Dan Politik JISoP 2(2):137-45.

Osborne, Stephen P., and Kerry Brown. 2012. Managing Change and Innovation in Public Service Organizations. USA and Canada: Routledge.

Rahmi, Helva, Siti Rahmiati, and Fajar Ivan Dolly. 2019. “Analisis Indeks Kepuasan Masyarakat Pengguna Pelayanan Publik Pada Pemerintah Daerah Di." JASIORA Jurnal Administrasi Sosial Dan Humaniora 3(3):31-38.

Siyoto, Sandu. 2015. Dasar Metodologi Penelitian. Karanganyar: Literasi Media Publishing. Sulistyo, Indah Nur'aini, and Sotya Partiwi Ediwijoyo. 2020. "Analisis Kepuasan Masyarakat Terhadap Pelayanan Publik Berdasarkan Indeks Kepuasan Masyarakat Di Kantor Kecamatan Ayah Kabupaten Kebumen." Jurnal E-Bis (Ekonomi-Bisnis) 4(2):276-86.

Taufiqurokhman, and Evi Satispi. 2018. "Teori Dan Perkembangan Manajemen Pelayanan Publik." UMJ PRESS 2018266.

Wasistiono, Sadu. 2003. Kapita Selekta Penyelenggaraan Pemerintahan Daerah. Bandung: Fokusmedia. 